\title{
POTENTIAL MARKERS OF INSULIN RESISTANCE IN HEALTHY VS OBESE AND OVERWEIGHT SUBJECTS
}

\author{
Dagmar Horakova $^{\text {a*}}$, David Stejskal ${ }^{\mathrm{b}}$, Dalibor Pastuchace, Lenka Muchovaa ${ }^{\mathrm{a}}$, Vladimir Janout ${ }^{\mathrm{a}}$ \\ ${ }^{a}$ Department of Preventive Medicine, Faculty of Medicine and Dentistry, Palacky University Olomouc, Czech Republic \\ ${ }^{b}$ Department of Laboratory Medicine and Metabolic Out Patient Centre, Central Moravian Hospital, Prostejov, Czech \\ Republic \\ c Department of Sports and Exercise Medicine, Faculty of Medicine, Palacky University Olomouc \\ E-mail:dagmar.horakova@upol.cz
}

Received: November 12, 2010; Accepted with revision: August 30, 2010

Keywords: Insulin resistance/Adiponectin/a-FABP/ASP/QUICKI/HOMA/Healthy subjects/Obese subjects

Background. Insulin resistance can lead to the metabolic syndrome, which may have cardiovascular and metabolic consequences. The study aimed at verifying the serum concentration levels of the adipose tissue proteins adiponectin, adipocyte-fatty acid binding protein (a-FABP) and acylation stimulating protein (ASP), and the potential use of these markers for early diagnosis of insulin resistance.

Methods and results. Healthy subjects (Group A, $n=53$ ), overweight subjects (Group B, n = 29) and obese subjects (Group C, $\mathrm{n}=51$ ) were studied. Those in Groups B and C had symptoms of insulin resistance. The subjects were selected based on clinical and laboratory findings. The concentrations of adiponectin were highest in the healthy subjects in Group A $(14.18 \pm 6.99 \mathrm{mg} /)$, lower in the overweight subjects in Group B $(11.12 \pm 4.46 \mathrm{mg} / \mathrm{l})$ and lowest in the obese subjects in Group C $(8.15 \pm 2.70 \mathrm{mg} / \mathrm{l})$. The a-FABP values were lowest in Group A $(20.23 \pm 7.95 \mathrm{mg} / \mathrm{l})$, higher in Group B $(32.22 \pm 15.56 \mathrm{mg} / \mathrm{l})$ and highest in Group C $(40.43 \pm 23.31 \mathrm{mg} / \mathrm{l})$. The concentrations of ASP were lowest in the Group A healthy subjects $(43.01 \pm 22.78 \mathrm{nmol} / \mathrm{l})$, higher in the Group B overweight subjects (50.58 $\pm 25.57 \mathrm{nmol} / \mathrm{l})$ and highest in the Group C obese subjects $(54.70 \pm 26.41 \mathrm{nmol} / 1)$. Statistically significant correlation coefficients in subjects from all groups among the markers studied describe the highest correlation is between a-FABP and BMI $(r=0.48)$, adiponectin and QUICKI $(r=0.42)$, adiponectin and triacylglycerols $(r=-0.35)$, ASP and BMI $(\mathrm{r}=0.33)$ and adiponectin and BMI $(\mathrm{r}=-0.31)$.

Conclusions. The concentrations of all studied markers were different in the healthy subjects as compared to the overweight or obese ones. Adiponectin proved to be a good indicator of insulin sensitivity, the low concentration of which could signal the initial stage of insulin resistance. A-FABP proved to be a prominent marker of "adiposity" in association with the development of insulin resistance. ASP did not prove to show significant differences between the overweight and healthy subjects, but significant differences were found between the obese and healthy subject.

\section{INTRODUCTION}

Insulin resistance is considered to be responsible for the development of all constituents of the metabolic syndrome. Insulin resistance is a condition in which insulin is unable to ensure that glucose is efficiently used by peripheral tissues, especially in the muscle or liver. Insulin resistance is related to impaired cell signal transduction, i.e. insulin receptor function and complex postreceptor events in the cells. To a certain extent, the defect is genetically determined. However, the role of external factors such as nutrition or lifestyle has been increasing. Insulin resistance is considered to be a key feature present in the metabolic syndrome. Numerous definitions of the metabolic syndrome have been suggested since the original 1988 definition by Reaven ${ }^{1}$. According to the current definition proposed by the International Diabetes Federation and European Association for the Study of Diabetes, the metabolic syndrome is diagnosed if at least three of the following five criteria are present: abdominal obesity measured by waist circumference, hypertension, hypertriglyceridemia, hyperglycemia and high LDL cholesterol. Methods for diagnosing insulin resistance are generally demanding invasive procedures such as the euglycemic clamp technique with intravenous administration of glucose and insulin ${ }^{2}$. Therefore, more simple methods or markers are searched, as Bergman's minimal model ${ }^{3}$. During a single glucose load, the blood is taken, insulin and glycemia is investigated and used for calculation of insulin sensitivity index. This method is too complicated for use in clinical practice. There are various modifications for calculations of homeostatic models for insulin resistance by levels of insulinemia and glycemia, like HOMA IR ${ }^{4}$, which correlate with clamp test techniques. With the recent advances in understanding the pathogenesis of metabolic syndrome, researchers are increasingly turning their attention to the molecular level. In this context, the activity of adipose tissue as an endocrine organ has been studied. Adipose tissue is the source of many substances having an effect on the metabolism of glucose and lipids as well as influencing target tissue sensitivity to insulin. In recent years, other laboratory markers pro- 
duced by adipose tissue have been reported. These are directly related to the development of insulin resistance and may also predict its progression. Of the markers, it is possible to use adiponectin, a-FABP (adipocyte fatty acidbinding protein) and ASP (acylation stimulating protein) concentrations. The aim of this study was to verify the relationship of the above-mentioned adipokines to impaired insulin sensitivity.

\section{MATERIALS AND METHODS}

The study sample was composed of three groups - A, B and C. Group A contained 53 healthy subjects without clinical or metabolic signs of insulin resistance. Group B comprised 29 overweight subjects with BMI > 25 and $<30$, each of them showing one or more of the following abnormal findings confirming the development of insulin resistance: hypertension (systolic > $130 \mathrm{~mm} \mathrm{Hg}$, diastolic $>85 \mathrm{~mm} \mathrm{Hg}$ ), hyperglycemia (fasting glycemia > $6.1 \mathrm{mmol} / 1$ ) and hypertriglyceridemia (triacylglycerols $>$ $1.69 \mathrm{mmol} / \mathrm{l})\left(\right.$ ref. $\left.^{5}\right)$. Group C contained 51 obese subjects (BMI > 30), each of which had at least three abnormal findings connected with the metabolic syndrome, such as obesity, hypertension, hyperglycemia or type 2 diabetes and hypertriglyceridemia (Table 1). The diagnostic criteria of the National Cholesterol Education Program Adult Treatment Panel III Report ${ }^{5}$ were used to assess the presence of insulin resistance in the subjects. Blood pressure and BMI $\left(\mathrm{kg} / \mathrm{m}^{2}\right)$ were measured in all subjects.

The concentrations of insulin (DPC, USA), glucose, total cholesterol, HDL cholesterol, triacylglycerols, adiponectin, a-FABP and ASP (BioVendor Laboratory Medicine, Inc., Brno, Czech Republic) were analyzed in fresh serum from morning venous blood samples taken after a 12-hour fasting period. The blood samples were drawn under aseptic conditions from the cubital vein and the serum samples were then obtained in a cooling centrifuge at $3000 \mathrm{~g}$ at $4{ }^{\circ} \mathrm{C}$ and subsequently frozen at $-80{ }^{\circ} \mathrm{C}$. Concentrations of a-FABP and adiponectin were determined after defrosting of individual samples throughout the course of one day.

The human a-FABP ELISA kits were obtained from BioVendor Laboratory Medicine, Inc. (Brno, Czech Republic). The assay was conducted according to the manufacturer's instructions. The intra- and inter-assay variations were evaluated by measuring 3 different samples in replicates of 8 (a-FABP: [CV intra-assay $<4.8 \%$, CV inter-assay $<10 \%$ ], adiponectin: [CV intra-assay $<5 \%$, CV inter-assay $<6 \%$, ASP: [CV intra-assay $<7 \%, \mathrm{CV}$ inter-assay $<9 \%])$.

Table 1. Basic metabolic and clinical characteristics of subjects.

\begin{tabular}{|c|c|c|c|}
\hline & $\begin{array}{l}\text { Group A } \\
\text { Healthy } \\
(n=53) \\
\sigma^{\top} 13, \text { ㅇ } 40\end{array}$ & $\begin{array}{c}\text { Group B } \\
\text { Overweight } \\
(\mathrm{n}=29) \\
\text { o }^{\top} 12 \text {, 우 } 17\end{array}$ & $\begin{array}{l}\text { Group C } \\
\text { Obese } \\
(n=51) \\
o^{2} 23, \text { ㅇ } 28\end{array}$ \\
\hline Age (years) & $56.9 \pm 11.8$ & $62.8 \pm 12.1^{*}$ & $59.5 \pm 10.5$ \\
\hline Systolic pressure (mmHg) & $127.3 \pm 15.0$ & $142.9 \pm 17.9 * * *$ & $141.3 \pm 15.5^{* * *}$ \\
\hline Diastolic pressure (mmHg) & $76.9 \pm 8.9$ & $83.1 \pm 8.7 * *$ & $86.0 \pm 10.5 * * *$ \\
\hline Body Mass Index $\left(\mathrm{kg} / \mathrm{m}^{2}\right)$ & $24.6 \pm 2.9$ & $26.9 \pm 2.0 * * *$ & $34.8 \pm 4.9 * * *$ \\
\hline Glucose (mmol/l) & $5.70 \pm 0.77$ & $8.03 \pm 2.62 * * *$ & $7.19 \pm 1.82 * * *$ \\
\hline Insulin (mIU/1) & $9.83 \pm 5.00$ & $14.02 \pm 11.53$ & $19.64 \pm 11.24 * * *$ \\
\hline Cholesterol (mmol/1) & $5.65 \pm 1.25$ & $4.99 \pm 1.27 *$ & $5.04 \pm 1.14^{* *}$ \\
\hline Triacylglycerols (mmol/1) & $1.46 \pm 0.75$ & $1.89 \pm 1.32 *$ & $2.36 \pm 1.12 * * *$ \\
\hline HDL - cholesterol (mmol/1) & $1.73 \pm 0.34$ & $1.58 \pm 0.33$ & $1.38 \pm 0.29 * * *$ \\
\hline QUICKI & $0.341 \pm 0.031$ & $0.316 \pm 0.033 * *$ & $0.301 \pm 0.023 * * *$ \\
\hline HOMA & $2.53 \pm 1.40$ & $5.26 \pm 4.71 * *$ & $6.50 \pm 5.13 * * *$ \\
\hline Adiponectin (mg/1) & $14.18 \pm 6.99$ & $11.12 \pm 4.46$ & $8.15 \pm 2.70 * * *$ \\
\hline aFABP (mg/l) & $20.23 \pm 7.95$ & $32.22 \pm 15.56 * * *$ & $40.34 \pm 23.31 * * *$ \\
\hline ASP (nmol/1) & $43.01 \pm 22.78$ & $50.58 \pm 25.57$ & $54.70 \pm 26.41 * *$ \\
\hline
\end{tabular}

$* \mathrm{p}<0.05 \quad * * \mathrm{p}<0.01 \quad * * * \mathrm{p}<0.001 \quad$ (comparison with healthy subjects)

Overweight $\mathrm{BMI}>25$ and $<30$ obese $\mathrm{BMI}>30$

The variables are presented as mean values $\pm \mathrm{SD}$

QUICKI $=1 /(\log$ fasting insulin $(\mu \mathrm{IU} / \mathrm{ml})+\log$ fasting glucose $(\mathrm{mg} / 100 \mathrm{ml}))$

HOMA = fasting insulin $(\mu \mathrm{IU} / \mathrm{ml}) \times$ fasting glucose $(\mathrm{mmol} / \mathrm{l}) / 22.5)$ 
The QUICKI and HOMA indexes were calculated according to the following formulas:

QUICKI $=1 /[\log$ fasting insulin $(\mu \mathrm{IU} / \mathrm{ml})+\log$ fasting glucose $(\mathrm{mg} / 100 \mathrm{ml})]$

HOMA = fasting insulin $(\mu \mathrm{IU} / \mathrm{ml}) \times$ fasting glucose $(\mathrm{mmol} / \mathrm{l}) / 22.5$.

\section{Statistical analysis}

The data obtained were processed using the Statistica 6 software. A p-value of $<0.05$ was considered statistically significant. Spearman's rank correlation coefficients were used to establish the association between adiponectin, a-FABP and ASP levels and parameters of the metabolic syndrome. Comparison of the values of metabolic syndrome parameters in the subjects was made using the Mann-Whitney U test. All data are expressed as mean values $\pm \mathrm{SD}$.

\section{RESULTS}

Table 1 describes the basic metabolic and clinical characteristics of all subjects in Groups A, B and C. The healthy subjects in Group A proved to be within the physiological parameters in all the tests performed, the only exception being total cholesterol which was slightly increased (5.65 mmol/1). The overweight subjects in Group $\mathrm{B}$ had findings typical for incipient insulin resistance, such as systolic hypertension, hyperglycemia and hypertriglyceridemia. However, their diastolic pressure, total cholesterol and HDL cholesterol concentrations were within the normal limits. The range of symptoms related to the development of insulin resistance is based on the defined metabolic changes in the organism ${ }^{6}$. The obese subjects in Group $\mathrm{C}$ all had abnormal findings of both systolic and diastolic hypertension, hypertriglyceridemia and hyperglycemia or type 2 diabetes, proving the presence of insulin resistance, whereas their total cholesterol and HDL cholesterol concentrations were found to be normal.

The concentrations of the studied markers (adiponectin, a-FABP and ASP) in Group A were considered normal for healthy middle-aged individuals. Furthermore, the QUICKI and HOMA homeostatic indexes also showed values typical for healthy individuals without signs of insulin resistance ( 0.341 and 2.53 , respectively). As shown in Table 1, the concentrations of ASP are lowest in the healthy subjects in Group A (43.01 nmol/1), higher in the overweight subjects with some abnormal findings of insulin resistance in Group B (50.58 nmol/1) and highest in the obese subjects with abnormal findings of insulin resistance in Group C (54.70 nmol/1).

The same pattern can be seen in a-FABP concentrations, being lowest in Group A $(20.23 \mathrm{mg} / 1)$, higher in Group B (32.22 mg/1) and highest in Group C (40.34 mg/1).

The results of the adiponectin tests showed an inverse pattern with the highest concentrations being in the healthy subjects in Group A (14.8 mg/1), lower in the overweight subjects in Group B (11.12 mg/l) and lowest in the obese subjects in Group C $(8.15 \mathrm{mg} / 1)$.

The QUICKI index was within the defined normal range in the Group A healthy subjects (0.341), decreased in the Group B overweight subjects (0.316) and even lower in the Group C obese subjects (0.301). Lower values are typical for individuals with signs of insulin resistance. The HOMA index in the healthy subjects in Group A (2.53) was lower than 2.68, the defined normal upper limit for healthy individuals ${ }^{7}$. Increased levels in Groups B (5.26) and $\mathrm{C}$ (6.50) also suggested an incipient development of insulin resistance in those subjects.

Table 2 indicates statistically significant correlation coefficients in subjects from all groups among the markers studied as well as selected parameters of insulin resistance. The highest correlation is between a-FABP and BMI $(\mathrm{r}=0.48)$, adiponectin and QUICKI $(\mathrm{r}=0.42)$, adiponectin and triglycerides $(r=-0.35)$, ASP and BMI $(r=0.33)$ and adiponectin and $\mathrm{BMI}(\mathrm{r}=-0.31)$.

\section{DISCUSSION}

Given the worldwide obesity epidemic, there is a real danger that the metabolic syndrome and its clinical consequences (atherosclerosis, hypertension, type 2 diabetes, dyslipidemia and others) will, in the near future, lead to an increase in cardiovascular morbidity and mortality in younger age categories ${ }^{8}$. The key problem is the early diagnosis of insulin resistance, allowing a number of preventive measures to improve lifestyle and nutrition as well as the pharmacological impact of insulin resistance and its clinical metabolic consequences.

The mean blood pressure and glycemia values of the Group C subjects were slightly lower than those in Group

Table 2. Statistically significant correlation coefficients among the markers studied (adiponectin, aFABP, ASP) as well as selected parameters of insulin resistance.

\begin{tabular}{|l|c|c|c|c|c|c|c|}
\hline & $\begin{array}{c}\text { Body Mass } \\
\text { Index }\end{array}$ & Glucose & Insulin & Triacylglycerols & $\begin{array}{c}\text { HDL } \\
\text { cholesterol }\end{array}$ & QUICKI & HOMA \\
\hline Adiponectin & $-0.31 * * *$ & $-0.27 * * *$ & $-0.29 * * *$ & $-0.35 * * *$ & $0.22 * * *$ & $0.42 * * *$ & $-0.28 * * *$ \\
\hline aFABP & $0.48 * * *$ & $0.20 *$ & $0.26 * *$ & $0.25 * *$ & $-0.20 *$ & $-0.30 * * *$ & $0.26 * *$ \\
\hline ASP & $0.33 * * *$ & $0.16 *$ & - & - & - & - & - \\
\hline
\end{tabular}

$* \mathrm{p}<0.05 \quad * * \mathrm{p}<0.01 \quad * * * \mathrm{p}<0.001$ 
B, probably due to treatment of hypertension and/or type 2 diabetes in some subject in Group C.

The relations between individual constituents of the metabolic syndrome suggest their common pathogenesis, with adipose tissue acting as an active endocrine organ playing an important role. Central deposition of fat with a high $\mathrm{W} / \mathrm{H}$ ratio, i.e. android obesity, is associated with insulin resistance. Therefore, certain proteins produced in adipose tissue may be used for diagnostic purposes. As insulin resistance develops, serum leptin increases significantly and the serum concentration of leptin receptors drops ${ }^{9}$. With the development of insulin resistance, the role of TNF $\alpha$ is observed, with the concentration rising in obese individuals with an increase in $\mathrm{BMI}^{10}$. These metabolic changes signalize negative clinical consequences. Adiponectin proves to be an appropriate biomarker connecting the constituents of metabolic syndrome as well as an indicator useful in the monitoring of insulin sensitivity $^{9}$. Adiponectin plays a role in determining glucose and lipid homeostasis and acts against a number of risk factors connected with obesity. Plasma adiponectin concentrations tend to be lower in those who are obese, have type 2 diabetes or coronary artery disease and the metabolic syndrome. In the overweight and obese individuals with signs of insulin resistance, the adiponectin concentrations were significantly lower than those in the healthy subjects. Those who had already developed the metabolic syndrome had plasma adiponectin concentrations under $4 \mathrm{mg} / 1$ (ref. $\left.{ }^{11}\right)$. Given all the metabolic parameters studied, adiponectin proved to have the highest correlation coefficient with the QUICKI homeostatic index, supporting their validity as indicators for the monitoring of insulin sensitivity ${ }^{12}$. A positive correlation of adiponectin and homeostatic indexes, low adiponectin concentration and increased leptin levels are characteristic for patients with the metabolic syndrome and type 2 diabetes ${ }^{13}$. The adiponectin-leptin ratio seems to be a good marker of insulin resistance which is even more sensitive than the HOMA and QUICKI homeostatic indexes ${ }^{14}$.

Our results show that a-FABP concentrations significantly positively correlate with BMI. In the obese subjects with signs of insulin resistance, the concentration was double that of healthy subjects $(40.34 \mathrm{mg} / 1 \mathrm{vs}$. $20.23 \mathrm{mg} / 1)$. Similar results were obtained in our previous study ${ }^{15}$. These results support the hypothesis that aFABP could be a contributing factor to the development of hypertriglyceridemia, glucose intolerance and insulin resistance $^{16}$.

ASP, a hormone produced by adipocytes, plays an important role in lipid metabolism ${ }^{17}$. Concentrations in the obese subjects with insulin resistance were higher than those in the healthy subjects $(54.70 \mathrm{nmol} / 1 \mathrm{vs}$. 43.01 nmol/1), although the differences were not as marked as in the case of a-FABP. Moreover, the difference in concentrations between the obese and overweight subjects was small, which is in accordance with the findings of Yang ${ }^{18}$ who did not discover a marked difference in ASP concentrations between obese diabetics and diabetics with normal body weight. Also, the correlation between ASP and BMI was smaller than that between a-FABP and BMI.
There were no correlations between the ASP and other metabolic parameters.

Changes in plasma adipokines can also be seen in very young obese children ${ }^{19}$, which may predispose them to increased fat deposition (ASP) and decreased fat oxidation (adiponectin).

The QUICKI homeostatic index correlated with adiponectin concentrations, which supports its use for the early detection of insulin resistance. Also, the HOMA homeostatic index proved to have the ability to differentiate between subjects with signs of insulin resistance and healthy subjects.

\section{CONCLUSION}

The concentrations of all the studied markers (adiponectin, a-FABP and ASP) differed when comparing the healthy subjects to the overweight or obese subjects. Adiponectin proved to be a good indicator of insulin sensitivity. Its low concentrations could signal the beginning of insulin resistance. A-FABP proved to be a prominent marker of "adiposity" in association with the development of insulin resistance. ASP did not prove to show a significant differences between the overweight and healthy subjects, but significant differences were found between the obese and healthy subjects.

\section{ACKNOWLEDGEMENT}

This work was supported by the IGA MZ CR No. NT 11098 grant.

\section{REFERENCES}

1. Reaven G. Role of insulin resistance in human disease. Diabetes 1988; 37:1595-1607.

2. DeFronzo RA, Tobin JD, Andres R. Glucose clamp technique: a method for quantifying insulin secretion and resistance. Am J Physiol 1979; 237:E214-E223.

3. Bergman RN, Prager R, Volund A, Olefsky JM. Equivalence of the insulin sensitivity index in man derived by the minimal model method and the euglycemic glucose clamp. J Clin Invest 79, 1987; 790-800.

4. Mathews DR, Hosker JP, Rudenski AS, Naylor BA, Treacher DF, Turner RC. Homeostasis model assessment: insulin resistance and beta-cell function from fasting plasma glucose and insulin concentrations in man. Diabetes Care 2002; 25(10):1891-2.

5. National Institutes of Health. Third report of the National Cholesterol Education Program (NCEP) Expert Panel on detection, evaluation and treatment of high blood cholesterol in adults (Adult treatment panel III). Washington DC: US Govt. Printing Office 2001, NIH publ. no. 01-3670.

6. Svacina S, et al. The metabolic syndrome. Praha: Triton; 2006.

7. Bonora E, Targher G, Alberiche M, Bonadonna RC, Saggiani F, Zenere MB, et al. Homeostasis model assessment closely mirrors the glucose clamp technique in the assessment of insulin sensitivity: studies in subjects with various degrees of glucose tolerance and insulin sensitivity. Diabetes Care 2000; 23:57-63.

8. De Vito E, La Torre G, Langiano E, Berardi D, Ricciardi G. Overweight and obesity among secondary school children in Central Italy. Eur J Epidemiol 1999; 15: 649-654. 
9. Malincikova J, Stejskal D, Hrebicek J. Serum leptin and leptin receptors in healthy prepubertal children: Relations to insulin resistance and lipid parameters, body mass index (BMI), tumor necrosis factor $\alpha(\mathrm{TNF} \alpha)$, heart fatty acid binding protein (hFABP), and IgG anticardiolipin (ACL-IgG). Biomed Pap Med Fac Univ Palacky Olomouc Czech Repub 2000; 143:51-57.

10. Gwozdziewiczova S, Lichnovska R, Ben Yahia R, Chlup R, Hrebicek J. TNF- $\alpha$ in the development of insulin resistance and other disorders in metabolic syndrome. Biomed Pap Med Fac Univ Palacky Olomouc Czech Repub 2005; 149:109-117.

11. Ryo M, Nakamura T, Kihara S, Kumada M, Shibazaki S, Takahashi $\mathrm{M}$, et al. Adiponectin as a biomarker of the metabolic syndrome. Circulation Journal 2004; 68: 975-981.

12. Hrebicek J, Janout V, Malincikova J, Horakova D, Cizek L. Detection of insulin resistance by simple quantitative insulin sensitivity check index QUICKI for epidemiological assessment and prevention. J Clin Endocrinol Metab 2002; 87:144-147.

13. Lee JM, Kim SR, Yoo SJ, Hong OK, Son HS, Chang SA. The relationship between adipokines, metabolic parameters and insulin resistance in patients with metabolic syndrome and type 2 diabetes. J Int Med Res 2009; 37:1803-1812.
14. Zaletel J, Barlovic DP, Prezelj J. Adiponectin-leptin ratio: a useful estimate of insulin resistance in patients with type 2 diabetes. $\mathrm{J}$ Endocrinol Invest 2010; in press.

15. Stejskal D, Karpisek M. Adipocyte fatty acid binding protein in a Caucasian population: a new marker of metabolic syndrome? Eur J Clin Invest 2006; 36:621-625.

16. Llaverias G, Noe V, Penuelas S, Vazquez-Carrera M, Sanchez RM Laguna JC, et al. Atorvastatin reduces CD68, FABP4, and HBP expression in oxLDL-treated human macrophages. Biochem Biophys Res Commun 2004; 318:265-274.

17. Ahren B, Havel PJ, Pacini G, Cianflone K. Acylation stimulating protein stimulates insulin secretion. Int J Obes Relat Metab Disord 2003; 27:1037-1043.

18. Yang Y, Lu HL, Zhang J, Yu HY, Wang HW, Zhang MX, et al. Relationships among acylation stimulating protein, adiponectin and complement $\mathrm{C} 3$ in lean vs obese type 2 diabetes. Int $\mathrm{J}$ Obes (Lond) 2006; 30:439-446.

19. Cianflone K, Lu H, Smith J, Yu W, Wang H. Adiponectin, acylation stimulating protein and complement $\mathrm{C} 3$ are altered in obesity in very young children. Clin Endocrinol 2005; 62:567-572. 
